Proceedings

\title{
Fabrication of An All-Solid-State Ammonium Ion- Selective Electrode by a Two-Step Process Using Cyclic Voltammetry ${ }^{\dagger}$
}

\author{
Abdelmohsen Benoudjit, Firdaus Abd-Wahab and Wan Wardatul Amani Wan Salim* \\ Department of Biotechnology Engineering, Faculty of Engineering, International Islamic University Malaysia, \\ Gombak, Kuala Lumpur 50728, Malaysia; \\ * Correspondence: asalim@iium.edu.my; Tel.: +60-16-444-5364. \\ + Presented at the 1st International Electronic Conference on Biosensors, 2-17 November 2020; Available \\ online: https://iecb2020.sciforum.net/.
}

Received: date; Accepted: date; Published: date

\begin{abstract}
Ammonium ion $\left(\mathrm{NH}_{4}^{+}\right)$is one of the indicators of water quality; high ammonium concentration $\left[\mathrm{NH}_{4}{ }^{+}\right]$in water can cause eutrophication, affect aquatic biota, and cause cell death in the central nervous system of human beings. However, current ion-selective electrodes used for water-quality monitoring are bulky, require frequent calibration owing to membrane fouling, and cannot be integrated into mobile sensor platforms. We fabricated an all-solid-state ion-selective electrode (AS-NISE) for ammonium ion using a two-step process; the first step is electropolymerization deposition on the electrode using a solution of 3,4-ethylenedioxythiophene (EDOT), sodium polystyrene sulfonate (NaPSS), and lithium perchlorate $\left(\mathrm{LiCLO}_{4}\right)$, resulting in a solid-state transducer on screen-printed carbon electrodes (SPCEs), and the second is electropolymerization deposition of EDOT, NaPSS, and o-phenylenediamine (o-PD) as ammonium ion-selective membrane (NISM) on top of the transducer. The electropolymerization deposition of the transducer and the NISM were simply achieved by cyclic voltammetry (CV) with potential from $0.0 \mathrm{~V}$ to $0.8 \mathrm{~V}$ and $50 \mathrm{mVs}^{-1}$ scan rates. The fabricated $\mathrm{NH}_{4}^{+} \mathrm{ISE}$ can detect $\left[\mathrm{NH}_{4}{ }^{+}\right]$as low as $5.7 \times 10^{-5}$ $\mathrm{M}$, with slope of $61.9 \mathrm{mV} /$ decade $\left(\mathrm{R}^{2}>0.99\right)$ and a linear range from $10^{-3} \mathrm{M}$ to $1 \mathrm{M}$. These preliminary results provide an initial insight into the applicability of the simple two-steps fabrication process of $\mathrm{NH}_{4}{ }^{+}$ISEs for scaling-up purposes, with the ability for miniaturization and integration into a mobile sensor platform.
\end{abstract}

Keywords: all-solid-state ion-selective electrode; electropolymerization; ammonium ion; cyclic voltammetry; EDOT

\section{Introduction}

Ammonium ions $\left(\mathrm{NH}_{4}{ }^{+}\right)$can present as a form of dissolved nitrogen generated by heterotrophic bacteria in water bodies. Ammonium can be a primary nitrogenous end product from the decomposition of $\mathrm{N}$-organic compounds such as proteins. The concentration of $\mathrm{NH}_{4}{ }^{+}$can increase rapidly in water as these ions are photosynthetically assimilated, stored, transformed, and excreted by aquatic organisms. Therefore, $\mathrm{NH}_{4}{ }^{+}$concentrations can indicate zones with high biogeochemical activity [1], and real-time and continuous monitoring of ammonium using sensors is required at such places.

Among the ion sensors, all-solid-state ion-selective electrodes (AS-ISEs) for $\mathrm{NH}_{4}{ }^{+}$are flexible, provide in-situ and real-time measurement, and can be miniaturized for integration into mobile platforms [2-5]. Ion-selective membranes (ISMs) as the sensing element in AS-ISE has been a crucial part in the fabrication process that determine sensors selectivity [6]. Traditionally, ISM is fabricated 
using a cocktail of materials consisting of plyometrics, plasticizers, ionophores, and stabilizers that are drop-cast onto the working electrode [6-8]. However, the drop-casting method suffers from weak adhesion of the drop-casted material to the electrode surface and shorter sensor lifetime [3,9] which could not be suitable in situations requiring continuous measurement in aqueous media.

Conducting polymers (CPs) have been used on the fabrication of AS-ISE due to their favorable ion to electron conductivity property $[10,11]$, and it can be electropolymerized and deposited on electrode surfaces [9,12], which could enhance the life-time of the AS-ISE. A study showed that a conductive polymer Poly (o-phenylenediamine) (PoPD) was successfully electropolymerized and deposited as ISM for $\mathrm{NH}_{4}^{+}$detection and it is contributed to the lifetime of the sensor [3]. However more studies are needed for miniaturization and scaling up purpose.

The aim of this work is to investigate the performance of the AS-NISE fabricated using a twostep process; first is electropolymerization deposition (EPD) of PEDOT:PSS transducer, and the second is EPD of PoPD-PEDOT:PSS onto a screen-printed carbon electrode as ion-selective membrane.

\section{Materials and Methods}

\subsection{Materials}

Electrochemical characterization was performed using a portable PocketSTAT ${ }^{\text {TM }}$ (IVIUM Technologies, Eindhoven, The Netherlands). A compatible voltammetry cell for screen-printed electrodes was purchased from PINE Research Instruments, Grove City, PA, USA. The working electrode (WE) diameter is two millimeters. Monomer 3,4-ethylenedioxythiophene (EDOT) was purchased from Apical Scientific, Seri Kembangan, Selangor, Malaysia. Poly(sodium 4styrenesulfonate) solution (NaPSS), lithium perchlorate powder $\left(\mathrm{LiClO}_{4}\right)$, and potassium ferricyanide $\left(\mathrm{K}_{3}\left[\mathrm{Fe}(\mathrm{CN})_{6}\right]\right)$ were purchased from Sigma-Aldrich, St. Louis, MO, USA. Furthermore, ophenylenediamine (o-PD) and ammonium chloride were purchased from Santa Cruz Biotechnology, Dallas, Texas, USA. Deionized (DI) water was used throughout the experiments. All measurements were performed in ambient conditions, at room temperatures of 25 to $28{ }^{\circ} \mathrm{C}$ and humidity of 59 to $65 \%$.

\subsection{Fabrication of All-Solid-State Ammonium Ion-Selective electrode (AS-NISE)}

SPCEs were activated using repetitive cyclic voltammetry (CV) for 3 cycles in $0.1 \mathrm{~N} \mathrm{H}_{2} \mathrm{SO}_{4}$ at extreme anodic and cathodic potentials of 2.5 to $-2.5 \mathrm{~V}$ and a scan rate of $100 \mathrm{mV} / \mathrm{s}$ [13]. The activated SPCEs were rinsed in DI water and left to dry for $24 \mathrm{hrs}$ in ambient conditions. The fabrication process of AS-NISE involves two steps. The first step is the electropolymerization deposition (EPD) by cyclic voltammetry (CV) of a PEDOT:PSS transducer onto the WEs of SPCEs, with a potential of 0 to $0.8 \mathrm{~V}$, and a scan rate of $50 \mathrm{mV} / \mathrm{s}$ for 5 cycles in $0.5 \mathrm{~mL}$ EDOT, $1 \mathrm{~mL} \mathrm{NaPSS}$, and $13.5 \mathrm{~mL} \mathrm{LiClO} 4(0.1 \mathrm{M})$. The modified electrode was washed with deionized water and left to air dry at ambient temperature. During the second step, a mixture of EDOT, NaPSS, and o-PD was deposited by CV method onto the PEDOT:PSS transducer to act as an ammonium ion-selective membrane (NISM). The CV was performed with a potential of 0 to $0.8 \mathrm{~V}$ and a scan rate of $50 \mathrm{mV} / \mathrm{s}$ for 5 cycles of scanning in the previous transducer solution containing $0.130 \mathrm{~g}$ o-phenylenediamine solubilized by $2 \mathrm{~mL} \mathrm{HCl}(1 \mathrm{M})$. The fabricated all-solid-state ammonium ion-selective electrode (AS-NISE) was rinsed carefully with DI water and activated in $10^{-3} \mathrm{M} \mathrm{NH}_{4} \mathrm{Cl}$ for six hours before use. 


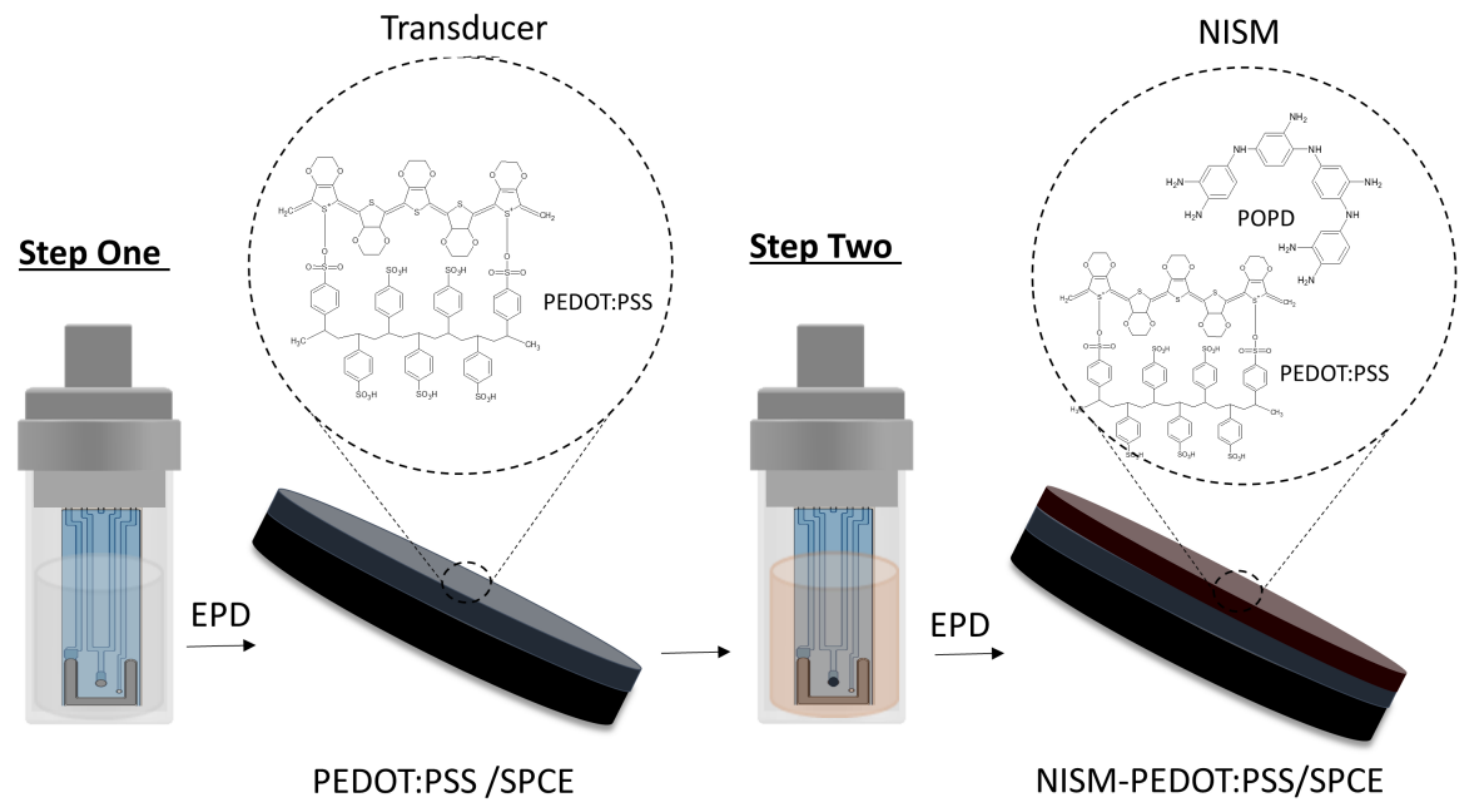

Figure 1. AS-NISE for ammonium-ion detection fabricated by electropolymerization deposition of conductive polymers.

\subsection{PEDOT:PSS Transducer Characterization}

Surface morphology of electropolymerized deposited PEDOT:PSS on SPCEs was observed using a scanning electron microscopy (SEM, JSM-IT100, JEOL, JAPAN) available at the Metallography Lab, Faculty of Engineering, IIUM, Kuala Lumpur, Malaysia. The electrodes were coated with goldpalladium particles using the Quorum SC7620 sputter coater. CV was performed using a PocketSTAT ${ }^{\mathrm{TM}}$ to evaluate the electron-transfer capabilities of the electropolymerized deposited PEDOT:PSS onto the WE of a SPCE as transducer by measuring the magnitude of the anodic peak current, peak potential drift, and reversibility behavior. $\mathrm{CV}$ was conducted in $0.1 \mathrm{M}$ potassium ferricyanide $\left(\mathrm{K}_{3} \mathrm{Fe}(\mathrm{CN})_{6}\right) / 0.5 \mathrm{M} \mathrm{KCl}$ solution with a potential window of $-0.3 \mathrm{~V}$ to $+0.7 \mathrm{~V}$ and scan rate of $100 \mathrm{mV} / \mathrm{s}$.

\section{Results}

\subsection{PEDOT:PSS/SPCE Transducer}

SEM images show that a PEDOT:PSS-modified electrode has a nanoglobular morphology (Figure $2 \mathrm{~b}$ ) instead of the sponge-like morphology of a bare electrode (Figure 2a). The globular structure seen in PEDOT:PSS/SPCE confirmed the deposition of PEDOT:PSS onto the WE of the SPCE. The change in the morphology of a PEDOT:PSS/SPCE was validated by CV measurements. At a scan rate of $100 \mathrm{mV} / \mathrm{s}$, the PEDOT:PSS/SPCE $\left(\mathrm{Ip}_{\mathrm{a}}=482 \mu \mathrm{A}\right)$ demonstrated an increase of oxidation peak current compared to a bare electrode $\left(\mathrm{Ip}_{\mathrm{a}-\mathrm{Bare}}=233 \mu \mathrm{A}\right)$. This higher peak current of PEDOT:PSS/SPCE results from the electrical conductivity of PEDOT:PSS. Furthermore, the difference in $C V$ anodic peak current $\left(\triangle \mathrm{I} \mathrm{p}_{\mathrm{a}}\right)$ between the bare electrode and PEDOT:PSS/SPCE was calculated from CV graphs (Figure 2c,d) to determine the effect of PEDOT:PSS on the peak current. The results showed that the peak current more than doubles $\left(\Delta \mathrm{I} p_{a}=249 \mu \mathrm{A}\right)$. Moreover, a shift of the anodic peak potential from Epa $=0.33 \mathrm{~V}$ (SPCE) to Epa $=0.29 \mathrm{~V}$ (PEDOT:PSS/SPCE) was observed. These results suggest that electropolymerized deposition of a PEDOT:PSS transducer improves electron transfer at the WE by increasing the peak current and decreasing the peak potential. 


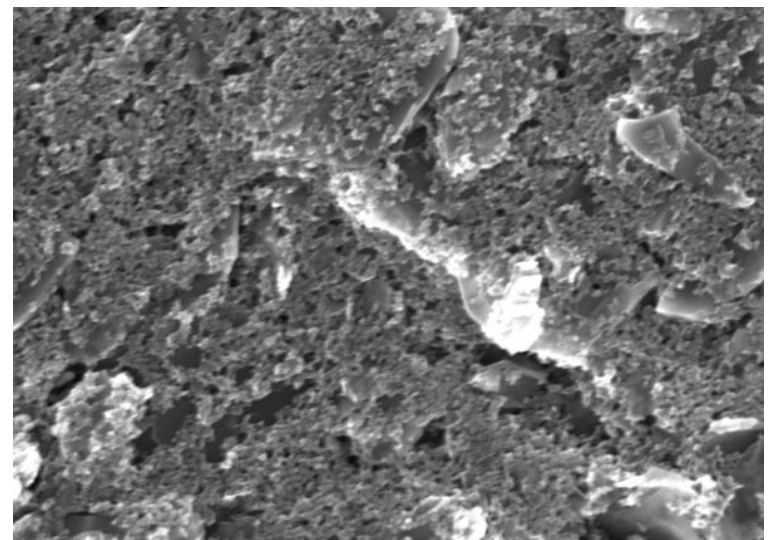

(a)

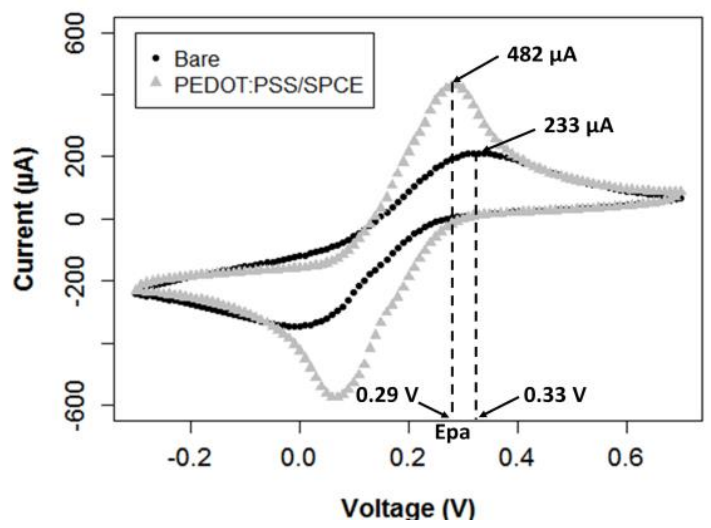

(c)

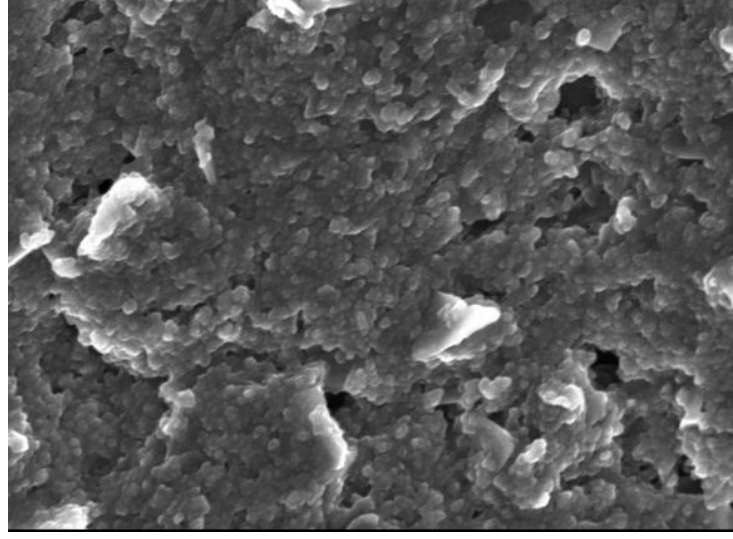

(b)

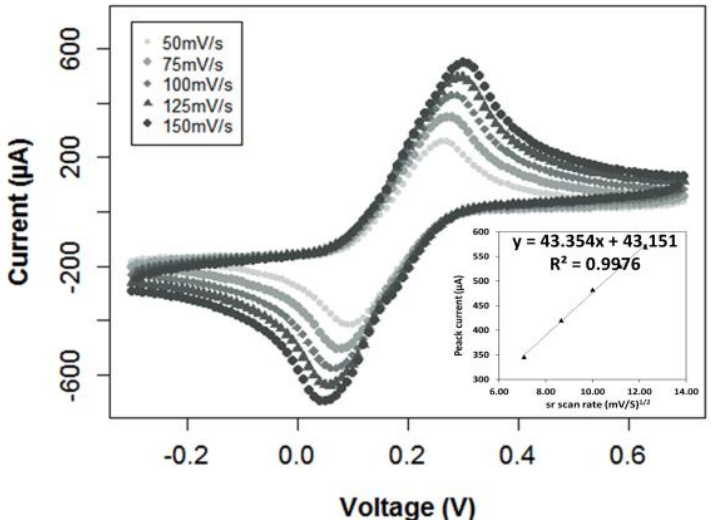

(d)

Figure 2. (a) SEM image of bare SPCE, (b) SEM image of the PEDOT:PSS/SPCE, (c) CV graphs in 0.1 $\mathrm{M} \mathrm{K} 3\left[\mathrm{Fe}(\mathrm{CN})_{6}\right]$ and $0.5 \mathrm{M} \mathrm{KCl}$ for bare SPCE and PEDOT:PSS/SPCE via EPD techniques at a scan rate of $100 \mathrm{mV} / \mathrm{s}$, and (d) PEDOT:PSS/SPCE at various scan rates (V/s) with linear regression between the peak current (Ip) and the square root of the scan rate $(\mathrm{mV} 1 / 2)$.

\subsection{Calibration Curve}

Figure 3a,b shows potentiometry measurements and calibration profile of the voltage changes versus log $\left[\mathrm{NH}_{4}{ }^{+}\right]$for PEDOT:PSS/SPCEs and NISM-PEDOT:PSS/SPCEs. In this study, we tested $\left[\mathrm{NH}_{4}{ }^{+}\right]$that ranged from $10^{-5}$ to $1 \mathrm{M} \mathrm{NH} 4 \mathrm{Cl}$. The results showed a linear relationship between voltage and $\left[\mathrm{NH}_{4}{ }^{+}\right]$added for both electrodes: $75.8 \mathrm{mV} /$ decade for PEDOT:PSS/SPCE, a super theoretical Nernst value that exceeds the theoretical Nernst value of $59.16 \mathrm{mV} /$ decade [7]. However, NISMPEDOT:PSS/SPCEs reported Nerst value of $61.9 \mathrm{mV} /$ decade that are closer to the theoretical value. NISM-PEDOT:PSS/SPCEs reached a detection limit of $5.7 \times 10^{-5} \mathrm{M}$, and a linear range of $10^{-3}$ to $1 \mathrm{M}$. The slope of a graph indicates the sensitivity of a sensor; a high slope means higher sensitivity. In this study, PEDOT:PSS/SPCEs showed the highest slope compared to NISM-PEDOT:PSS/SPCEs. However, the absence of NISM in PEDOT:PSS/SPCEs can lead to low ion selectivity. 


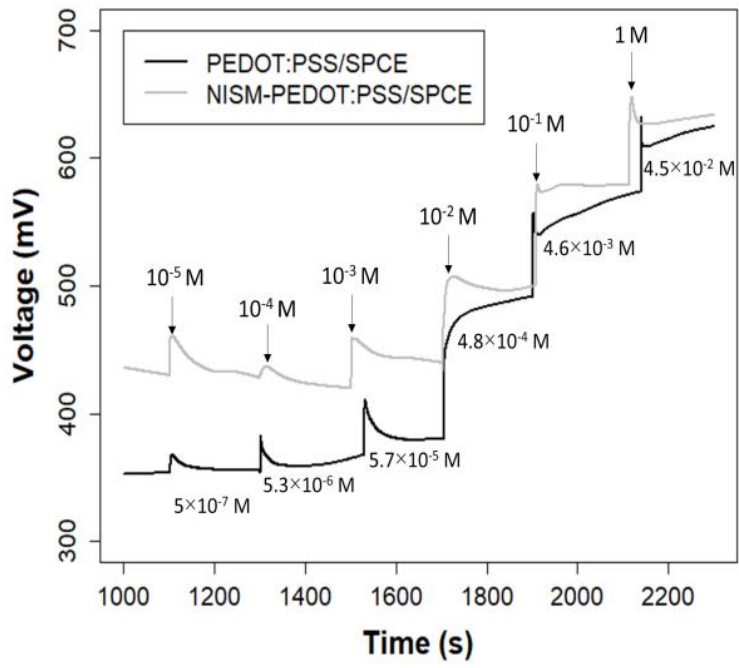

(a)

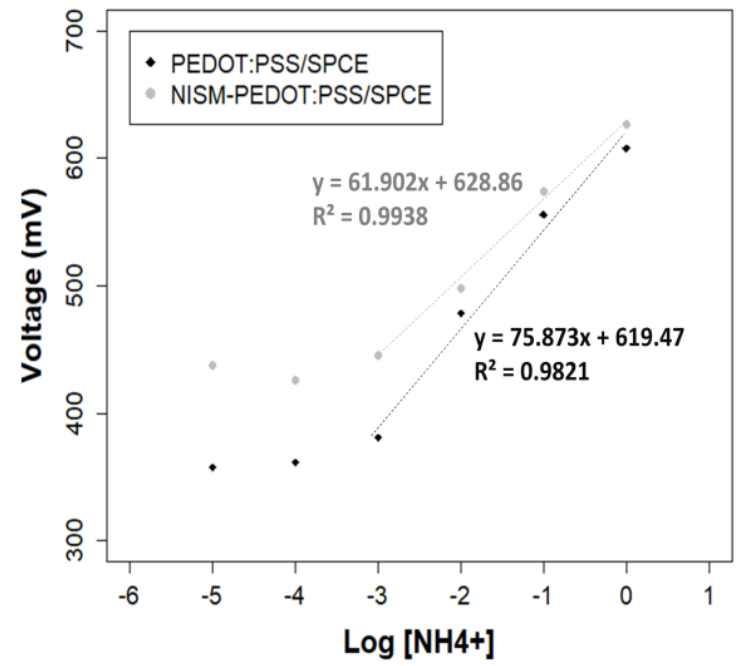

(b)

Figure 3. All-solid-state ammonium ion-selective electrode (AS-NISE) characterization. (a) Chronopotentiometry measurements, (b) calibration curve.

\section{Conclusions}

A NISM-PEDOT:PSS/SPCE for $\mathrm{NH}_{4}{ }^{+}$quantification was fabricated using a two-step process: electropolymerization deposition of the transducer and deposition of the ion-selective membrane. The NISM-PEDOT:PSS/SPCE showed a sensitivity of $61.9 \mathrm{mV} /$ decade, a value which is close to the theoretical Nernst value (59.16 $\mathrm{mV} /$ decades). The ammonium sensor exhibited a low detection limit of $5.7 \times 10^{-5} \mathrm{M}$ with a linear detection range from $5.7 \times 10^{-5}$ to $4.5 \times 10^{-2} \mathrm{M}$. These preliminary results provide an initial insight into the applicability of the simple two-step fabrication process of AS-NISEs. Future studies are warranted to determine the selectivity and chemical interaction between the components of AS-NISEs. Optimization of the electropolymerization deposition parameters is needed as well to expand this work for scaling-up purposes, with the ability for miniaturization and integration to a mobile sensor platform.

Acknowledgments: The authors would like to thank members of Amani Research Group (ARG) for their support. This work is being supported by nanoSkunkWorkX Sdn. Bhd.

\section{References}

1. Delwiche, C.C. The nitrogen cycle. Sci. Am. 1970, 223, 136-147.

2. Athavale, R.; Kokorite, I.; Dinkel, C.; Bakker, E.; Wehrli, B.; Crespo, G.A.; Brand, A. In situ ammonium profiling using solid-contact ion-selective electrodes in eutrophic lakes. Anal. Chem. 2015, 87, 11990-11997.

3. Cuartero, M.; Crespo, G.A. All-solid-state potentiometric sensors: A new wave for in situ aquatic research. Curr. Opin. Electrochem. 2018, 10, 98-106.

4. Kan, Y.T.; Han, C.H.; Ye, Y.; Zhang, X.; Huang, Y.; Xing, L.; Zhou, Y.; Qin, H. An all-solid-state ammonium ion-selective electrode based on polyaniline as transducer and poly (o-phenylenediamine) as sensitive membrane. Int. J. Electrochem. Sci. 2016, 11, 9928-9940.

5. Wu, R.; Salim, W.W.; Malhotra, S.; Brovont, A.; Park, J.; Pekarek, S.; Banks, M.K.; Porterfield, D.M. Selfpowered mobile sensor for in-pipe potable water quality monitoring. In Proceedings of the 17th International Conference on Miniaturized Systems for Chemistry and Life Sciences, 2013; pp. 14-16.

6. Bakker, E.; Pretsch, E. Modern potentiometry. Angew. Chem. Int. Ed. 2007, 46, 5660-5668.

7. Benoudjit, A.M.; Shohibuddin, I.U.S.; Bader, M.M.; Salim, W.W.A.W. Components of All-Solid-State IonSelective Electrodes (AS-ISEs). In Composite Materials: Applications in Engineering, Biomedicine and Food Science; Springer: Cham, Switzerland, 2020; pp. 351-366. 
8. Cuartero, M.; Colozza, N.; Fernández-Pérez, B.M.; Crespo, G.A. Why ammonium detection is particularly challenging but insightful with ionophore-based potentiometric sensors-an overview of the progress in the last 20 years. Analyst 2020, 145, 3188-3210.

9. Benoudjit, A.; Bader, M.M.; Salim, W.W.A.W. Study of electropolymerized PEDOT: PSS transducers for application as electrochemical sensors in aqueous media. Sens. Bio-Sens. Res. 2018, 17, 18-24.

10. Bobacka, J.; Ivaska, A.; Lewenstam, A. Potentiometric ion sensors based on conducting polymers. Electroanal. Int.l J. Devot. Fundam. Pract. Aspects Electroanal. 2003, 15, 366-374.

11. Bobacka, J. Conducting polymer-based solid-state ion-selective electrodes. Electroanal. Int. J. Devot. Fundam. Pract. Aspects Electroanal. 2006, 18, 7-18.

12. Sayyah, S.M.; El-Deeb, M.M.; Kamal, S.M.; Azooz, R.E. Electropolymerization of o-phenylenediamine on Pt-electrode from aqueous acidic solution: Kinetic, mechanism, electrochemical studies and characterization of the polymer obtained. J. Appl. Polym. Sci. 2009, 112, 3695-3706.

13. Screen-Printed Electrode Information-Carbon and Ceramic Electrode Information. Pine Res. Instrum. 2016, 10036, 1-10.

Publisher's Note: MDPI stays neutral with regard to jurisdictional claims in published maps and institutional affiliations.

(C) 2020 by the authors. Submitted for possible open access publication under the terms and conditions of the Creative Commons Attribution (CC BY) license (http://creativecommons.org/licenses/by/4.0/). 